\title{
Adoption of Electronic Supply Chain Management and E-Commerce by Small and Medium Enterprises and Their Performance: A Survey of SMEs in Pakistan
}

\author{
Shahzad Ahmad Khan1*, Yan Liang1, Sumaira Shahzad² \\ ${ }^{1}$ School of Economics and Management, China University of Geosciences, Wuhan, China \\ ${ }^{2}$ School of Geographic Information System, China University of Geosciences, Wuhan, China \\ Email: shezad80@gmail.com, yanliang@cug.edu.cn
}

Received 2 July 2014; revised 1 August 2014; accepted 1 September 2014

Copyright (C) 2014 by authors and Scientific Research Publishing Inc.

This work is licensed under the Creative Commons Attribution International License (CC BY). http://creativecommons.org/licenses/by/4.0/

c) (i) Open Access

\begin{abstract}
Adoption of E-Commerce and Electronic Supply Chain Management (E-SCM) by small and medium enterprises (SMEs) has developed a tremendous performance in business process. SMEs in Pakistan are trying to enhance their competences by adopting a new technology to enter into the global market. The survey was aimed to investigate the current status and future direction of the adoption and benefits of E-Commerce and E-SCM by small and medium enterprises in Pakistan. A mailed questionnaire survey was conducted to collect data from 210 SMEs as samples located in Karachi, Gujranwala and Faisalabad, Pakistan. The results suggest that E-Commerce and E-SCM adoption has a significant, positive influence on SMEs, who have significantly higher average sales growth rate, on-time order management and delivery process than non-adopters. The findings of this study can be useful for SMEs in general as a means of understanding how E-Commerce and E-SCM adoption positively affects the firm's performance.
\end{abstract}

\section{Keywords}

E-Commerce, Small and Medium Enterprises, E-Supply Chain Management, Pakistan

\section{Introduction}

Adoption of E-Commerce and E-Supply Chain Management (E-SCM) by Small and medium enterprises (SMEs)

"Corresponding author.

How to cite this paper: Khan, S.A., Liang, Y. and Shahzad, S. (2014) Adoption of Electronic Supply Chain Management and E-Commerce by Small and Medium Enterprises and Their Performance: A Survey of SMEs in Pakistan. American Journal of Industrial and Business Management, 4, 433-441. http://dx.doi.org/10.4236/ajibm.2014.49051 
has developed a great performance in business process. The use of Internet allows rapid exchange of information and the availability of reliable data, easy access and co-ordination among Business-to-Business (B2B) and Business-to-Customer (B2C). E-Commerce is a process of sales, product $\&$ business information and services of various products over internet. It is the fastest growing slice of our economic, which follows from smaller business to reach to global trade with product or message by cost saving. E-Commerce adoption is said to be a contributors to the advancement of business processes and has become a crucial considerations in SMEs nowadays. SMEs can consider E-Commerce as a strategic weapon to improve SCM and performance in the competitive marketplace. E-SCM is not only about technology changes but also involves changes in management policies, organizational structure, performance metrics, business processes across the supply chain [1]. The integration of E-Commerce in a supply chain management function that is carried out internally among SMEs by the members of the chain includes the application of basic internet services as well as the use of business management systems and E-business [2]. The integration of information technology with suppliers, firms sees them as an option to reduce costs by means of cooperative work [3]. On the other hand, service to the client is the most important attribute for success in the supply chain [4]. Clients are considered as a part of this success when they interact with the firm in the development of products and processes according to their needs. E-Commerce expands the traditional supply chain processes by extending its capabilities for the betterment of SMEs. To compete successfully in the marketplace today and better serve the customer demands, it is imperious for SMEs to adopt enabled comprehensive supply chain processes. E-Commerce has been a major technological innovation for developed countries and is spreading increasingly to developing countries like Pakistan.

\section{SMEs Sector in Pakistan}

In 1998, Government of Pakistan cognized the importance of SMEs for the contribution in economic growth and development of the economies formed Small \& Medium Enterprises Development Authority (SMEDA) as the leading organization meant to provide support to SMEs in Pakistan. SMEs have a significant contribution in the total GDP of Pakistan, according to SME Development Authority (SMEDA) and Economic survey reports; the share in the annual GDP is $40 \%$, share in manufacturing export $25 \%$ and SMEs providing significant employment opportunities for skilled workers and entrepreneurs. SMEs represent approximately $90 \%$ of all the enterprises in Pakistan and are providing the $82 \%$ jobs to those persons who are not employed in the agriculture sector in the different SMEs especially in the different parts of the country like Lahore, Sialkot, Faisalabad and Gujranwala. Areas of Sindh include Hyderabad and Karachi in particular and apart from these major city centers, there exist many different small scale enterprises in the remote areas of Kashmir [5]. According to Economic Survey of Pakistan that approximately 3.2 million SMEs are operating in the country and best contribute to economy. The Government of Pakistan is committed to develop the SMEs sector for achieving higher economic growth leading to the creation of jobs and poverty alleviation. SMEs development will be achieved by providing a superior business environment, greater access to formal financing and through provision of support in technical up gradation, human resource development, marketing and innovation.

The role of SMEs can't be neglected because it has great importance in the economies of many countries of the world. SMEs in Pakistan are trying to enhance their competences adopting new technology to enter into the global market. Recently, IFC (International Finance Corporation), a member of the World Bank Group, and Bank Alfalah have launched the SME Toolkit in Pakistan, an online solutions platform designed to help small and medium enterprises grow their business and improve their performance [6]. This SME Toolkit offers tools and expert advice on how to setup, trade and grow a business, as lack of access to relevant information and expertise is one of the key checks to the growth of SMEs in Pakistan. SMEs are expanding their use of electronic commerce is improving continually, shaped by the government policies already in place, the alteration of existing policies in the Internet environment and the introduction of policies to assist SMEs in meeting the challenges and opportunities posed by E-Commerce. SMEs in Pakistan increasingly uses the Internet for a variety of commercial purposes; many small retailer, wholesaler and producer choose to expand their business by joining virtual shopping mall. In addition, the adoption and utilization of E-SCM and E-Commerce can act as a strategic tool to help them to compete in a global market.

The main purpose of our study is to identify electronic SCM and E-Commerce technology adoption as well as benefits of implementation among SMEs in Pakistan. 


\section{Literature Review}

\subsection{E-commerce Adoption and SMEs' Performance}

E-Commerce is the process of transferring of products, buying, selling, services or exchanging information through the electronic medium [7]. The use of new manufacturing technologies, as in the case of digital operating machines, that can lead innovation in products and processes among SMEs [8]. Research in E-Commerce adoption has examined a number of internal and external factors influencing the adoption decision in SMEs [9]. E-Commerce facilitates the progress and growth of SMEs in developing countries due to the ability of the internet technology and ICT to reduce cost of transactions, to eliminate intermediaries and facilitating linkages to the global supply chains [10].

Many researchers used innovation diffusion theory as a framework to examine electronic data interchange (EDI) adoption [11]. Innovation diffusion theory is made up of various technological factors such as comparative advantage, complexity, capability, compatibility and trainability that may affect SMEs' decision to adopt information technology. Earlier works that utilized innovation diffusion theory focused on technological factors. E-Commerce contributes to business efficiency in five important ways. They are as follows: (a) shrinking distances and time cycle, (b) reducing distribution and transaction costs, (c) rapid product development, (d) facilitating more information to buyers and sellers and (e) expanding customer choice and supplier easy reach [12]. The vital argument is based on the fact that vertical cooperation with customer and suppliers plays an important role in processes of innovation among SMEs as shown in Figure 1 [13].

Many B2B and B2C SMEs are establishing an online channel and they are now concentrating on how to grow this channel to maximize revenue. SMEs using the Internet to set up or expand their Selling, purchasing operations and those offering new intermediate products and services need low-cost and reliable authentication and certification mechanisms to establish their online identity and reliability. Important efficiency gains are associated with the use of E-Commerce, arising from reductions in costs and supply chain management performance of business processes. E-Commerce provided the adopters with cost savings resulting from reduced paper transactions, reduced buyers' search, customer easiness, shorter order cycle time, and the consequent inventory reduction [14]. The development of effective E-Commerce strategies is of fundamental importance for success in domestic and global markets. The more compatible the sociocultural environment is the more extensive use of E-Commerce in Trade [15]. The process of E-Commerce adoption in SMEs is directly impacted upon top management where all decisions from daily tasks to future investments are made by them [16].

Researchers put their emphasis on E-Commerce activities, such as e-selling and e-purchasing; Hollenstein and Woerter [17], online shopping; Crespo and Bosque [18], e-travelling; Wang and Cheung [19], Online shopping/online banking/online investing and electronic payment for an internet service; Eastin [20]. Pakistan's first E-Commerce company was started by Abid Beli in 2001 with the establishment of Beliscity.com and made great effort to grow this industry in Pakistan, since then the market has grown steadily until 2014. Pakistan E-Commerce industry is worth estimated 4.5 billion PKR per year with the huge transactions taking place through cash

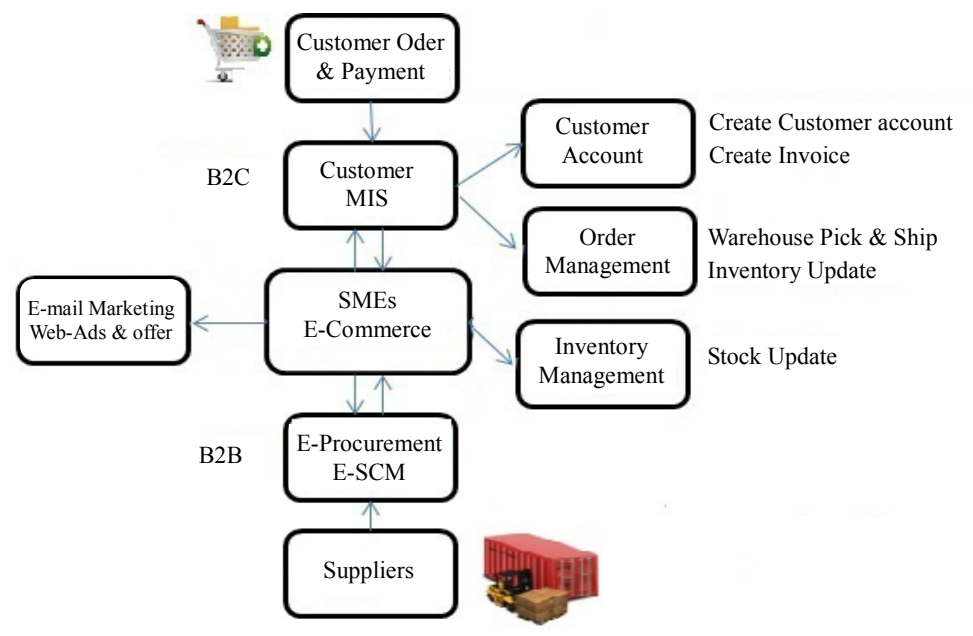

Figure 1. SMEs E-Commerce management process. 
on delivery (COD) to domestic customer (Venters.com). To cognized the importance of E-Commerce more than $20 \%$ Pakistani's SMEs implemented in their business to take competitive advantage not only from domestic market as well as global market.

\subsection{E-SCM and SMEs Performance}

Electronic supply chain management (E-SCM) is the collaborative use of Internet to enhance Business-toBusiness (B2B) and Business-to-Customer (C2C) processes and improve speed, agility, real-time control, and customer satisfaction. Internet infrastructures such as web-based information system, EDI, XML and ERP, and reliability of both hardware and software, are critical to E-SCM formation and effective communication among supply chain members [21] [22]. E-SCM in SMEs is a tactic that helps the organization to function in a more agile and cost effective manner by integrating the processes of various partners at all three levels - strategic, tactical, and operational. Even though globalization has increased pressure on SMEs to frequently reduce their prices against their quality and services. E-SCM can improve the performance of SMEs and growth their profitability by enhancing their ability to obtain supplies of the right quality, at the right time, and at the most favored prices. The primary objective of E-SCM is to minimize total system cost while satisfying service requirements and integration of all areas purchasing, customers queries, manufacturing, and warehousing in a SMEs. Electronic supply chain is to integrate all information either from customer's side or supplier's sides and to facilitate manufacturing products for sustaining requirement of the global environment or market place.

The electronic based application of SCM in SMEs will assist them to achieve lower operating costs, better service quality, reduce order cycle time, decrease inventory level, improve customer satisfaction and develop an overall competitive advantage [23]. The use of information technology in SMEs improve the operations of supply chain activities like procurement as well as the management of the supply chains like planning, coordination and control. In contrast, E-SCM is not about technology change also but also involves changes in management procedure \& policies, organizational culture, performance levels, business processes and organizational structure across the supply chain [24]. The performance and benefits of E-SCM for SMEs are obvious from previous studies, among them obtaining a competitive advantage through relationships between clients and suppliers [25].

More effective and efficient supply chain can be achieved by eliminating one or more intermediaries. B2B can act as an enabler that offers distinct competitive advantage. B2B e-marketplace provides SMEs with high supply chain power and high capabilities for online interactions. Economic benefits such as reduced time to market, reduced operating expenses, increased revenue growth and enhanced customer service level [26]. SCM have to create balance between downward cost pressures and the need for its efficiency. The effective supply chain means to response towards fluctuation of customer's demand quickly as shown in Figure 2 [27].

\section{Research Methodology}

\subsection{Sample}

In this research, the sample is the SMEs that were located at Karachi, Gujranwala and Faisalabad in Pakistan. The information about the SMEs was obtained from these cities chamber of commerce offices and drawn from membership lists. Quota sampling technique was chosen as the researcher's ease of access to the whole sample population [28]. Study respondents included the SMEs manager or the personnel responsible for the SMEs

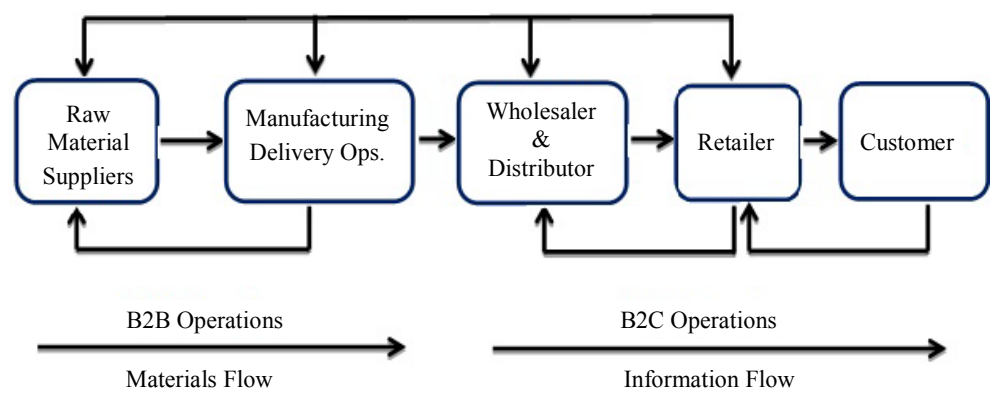

Figure 2. Electronic supply chain management (Vakharia 2002). 
operations in the organization because they tend to adopt such technologies and it was envisaged that interesting results could be obtained. 425 small and medium firms were selected from Service and as well as from manufacturing sector. Karachi, Gujranwala and Faisalabad were chosen as the sample for the study because it represents the important SMEs hub in Pakistan.

\subsection{Instrument Development}

Respondents were required to complete the survey that had the following major sections as:

a) It related to demographics information such as company details, contact person information, number of employees, total revenues earned and entire mode of operations.

b) This measured the E-Commerce technology adoption which includes the expansion and current status of ECommerce implementation.

c) It related to supply chain technology that consists of further subsections which include questions for supply chain technologies adoption and benefits of supply chain technologies.

\subsection{Data Collection}

In February 2014, a mailed questionnaire survey was conducted to the selected SMEs and cities in Pakistan. We sent questionnaire with covering letter, explaining the purpose of the study, assuring them for secrecy of their organization information. Stamped envelopes were enclosed to facilitate the return of the completed questionnaires. By final count, 210 valid responses out of 425 were received with a response rate of $49.5 \%$ for SMEs companies.

\section{Results}

\section{Final Reliability}

The reliability was checked by examining the Cronbach's $\alpha$ coefficient as Table 1 .

The Cronbach's $\alpha$ coefficients range from 0.75 to 0.917 , higher than the recommended 0.70 level which indicating acceptable level of reliability. So it is concluded that these construct that we intent to measure from the questionnaires is fit for measuring the instruments. This showed that the instrument was sufficiently reliable and could consistently capture true score variability among respondents.

a) Electronic Commerce Adoption and Benefits

Table 2 shows the benefits of E-Commerce adoption among SMEs. As of the results, it is clearly seen that SMEs has a relatively low level E-Commerce adoption in Pakistan with the mean value of (1.84 to 2.78). From the questionnaire results, it is find that many SMEs not interested to use E-Commerce as they are selling product to local market and others due to lack of trained staff but the SMEs those selling their product domestic as well as global are heavy user of E-Commerce. Some SMEs reveal limited understanding of the full range of benefits of E-Commerce. For this purpose SMEDA has been set up branches to provide comprehensive information,

Table 1. Reliability analysis for SMEs.

\begin{tabular}{|c|c|c|c|}
\hline Construct & Variables & No. of Items & Cronbach Alpha \\
\hline \multirow[t]{2}{*}{ E-Commerce } & Level of E-Commerce Adoption & 5 & 0.751 \\
\hline & E-Commerce Benefits & 5 & 0.91 \\
\hline \multirow[t]{3}{*}{ E-SCM } & Level of E-SCM Adoption & 3 & 0.835 \\
\hline & Benefits of E-SCM Adoption & 4 & 0.917 \\
\hline & Duration of E-SCM Adoption & 5 & 0.872 \\
\hline \multirow[t]{4}{*}{ SMEs Operation } & Productivity Improvement & 5 & 0.915 \\
\hline & improve in on-time Order Management & 4 & 0.867 \\
\hline & Improve in on-time delivery & 4 & 0.798 \\
\hline & Stock/inventory reduction & 5 & 0.845 \\
\hline
\end{tabular}


advice and training on business usage of the Internet as well as support services for the establishment of e-business activities.

b) Electronic Supply Chain Management Adoption and Benefits.

Table 3 results indicate the mean and SD scores and all the item measuring level of electronic supply chain adoption among SMEs. It can be valued that improve in on-time order management tops the list (3.05) followed by Stock/Inventory reduction (2.85) respectively for the level of SCM adoption in SMEs. This suggests that Supply chain functions in SMEs on-time order management has been seriously implement E-SCM by SMEs companies.

Table 4 shows that the mean and SD scores for each of the item measuring duration of E-SCM being adopted by SMEs. The mean score of 3.96 with a SD of 1.101 implies that the majority of SMES companies have consistently agreed that they have implemented E-SCM for more than a year with transportation represents the highest rate.

SMEs were asked to evaluate the benefits they had gained with regards to E-SCM adoption.

The result of Table 5 indicates that SMEs companies had perceived a high benefits from E-SCM adoption with the mean value of (1.82 and 1.92) respectively. The respondents mentioned reduced in cost for order processing, reduced time in delivery, improved customer service and reduction in stock/inventory as among the benefits of E-SCM adoption. SMEs are cognize the importance of the use of electronic supply chain management in business process.

\section{Table 2. Benefits of E-Commerce Adoption.}

\begin{tabular}{cc}
\hline E-Commerce Adoption \& Benefits & SMEs \\
\hline Mean \pm SD \\
\hline Our SMEs use EDI, ECM (Enterprise Content Management) or others software for processing. & $1.82 \pm 0.616$ \\
Our SMEs share information of product, price and promotion online & $1.84 \pm 0.603$ \\
Our SMEs use Internet for taking order and billing and automated tracking system for delivery. & $1.90 \pm 0.588$ \\
Our SMEs use ESCM (Electronic Supply Chain Management) and WMS (Warehouse Management System). & $1.92 \pm 0.577$ \\
\hline
\end{tabular}

Table 3. Level of E-SCM Adoption.

\begin{tabular}{cc}
\hline SMEs Operation & SMEs \\
\hline Productivity Improvement & Mean \pm SD \\
\hline Improve in on-time Order Management & $2.45 \pm 1.299$ \\
Improve in on-time delivery & $3.05 \pm 0.586$ \\
Stock/inventory reduction & $2.55 \pm 1.060$ \\
$1: 0 \%-25 \% ; 2: 26 \%-45 \% ; 3: 46 \%-65 \% ; 4: 66 \%-85 \% ; 5: 86 \%-100 \%$ \\
\hline
\end{tabular}

Table 4. Duration of E-SCM Adoption.

\begin{tabular}{cc}
\hline SMEs Operation & SMEs \\
\hline & Mean \pm SD \\
\hline Productivity Improvement & $3.45 \pm 0.930$ \\
Improve in on-time Order Management & $3.63 \pm 1.090$ \\
Improve in on-time delivery & $3.96 \pm 1.101$ \\
Stock/inventory reduction & $3.80 \pm 1.007$ \\
1: Still not Implemented; 2: 1 - 2 years ago; 3: 3 - 5 years ago; 4: More than 5 years
\end{tabular}


Table 5. Benefits of E-SCM Adoption.

\begin{tabular}{cc}
\hline Benefits & SMEs \\
\hline Reduced in cost for order processing & Mean \pm SD \\
Reduced time in delivery & $1.82 \pm 0.616$ \\
Improved customer service & $1.84 \pm 0.603$ \\
Stock/inventory reduction & $1.90 \pm 0.588$ \\
1: Strongly Agree 2: Agree 3: Neutral 4: Disagree 5: Strongly Disagree
\end{tabular}

\section{Discussion}

This study has investigated adoption and benefits of E-Commerce and E-SCM in small-and medium-sized enterprises in Pakistan. SMEs are key economic players and an effective source of national and local economic development. We found that the current status of E-Commerce adoption among SMEs to support E-SCM involving their suppliers and customers respectively. The results show that E-Commerce innovation and technological changes determine firm performance, productivity, and growth and the capacity of SMEs to reap the benefits of globalization. SMEs have begun to realize that with adoption of EDI and E-Commerce information obtain and fetch by one party can be directly fed into its home application system for planning and execution. In this way, SMEs would be able to enhance the level of customer service and reduce operating cost on both sides. Therefore, it is recommended that all SMEs companies start to develop their strategies of using E- Commerce to change the way business is being conducted.

From the survey result it was found that SMEs were more eager to adopt E-SCM for competitive advantage and execution of globalization business. For SMEs operations E-SCM could be a potential feature to improve on the materials flow and information flow between supplier and customer. Many SMEs are adopting E-SCM in various business processes such as transportation, warehousing and inventory management. The top four motivating factors for E-SCM adoption in SMEs are reduced the cost of processing orders, reduce time in delivery, reduce in stock/inventory and improved customer service so that they can plan their production more efficiently as we can see SMEs had gain a tremendous benefits in their inventory management and customer service.

\section{Conclusion and Recommendation}

The main purpose of the survey study was to investigate the current status of E-Commerce and E-SCM adoption among the SMEs and their performance in Pakistan. This study also found that encouraging implementation of E-Commerce at SMEs in Pakistan, has increased growth in sales revenue, timely order and delivery to customer, lowed expenses in developing and maintenance a website, and increased the numbers of customers. This study has shown that SMEs used E-SCM most extensively to support all the processes of their logistics activities. Furthermore, the adoption and utilization of E-Commerce and E-SCM can act as a strategic tool to help them to compete in a larger market. The results of the study indicate that the level of E-SCM and E-Commerce technology adoption among SMEs in Pakistan is not high and SMEDA should take initiatives to encourage more SMEs to implement E-Commerce and E-SCM in their organization environment. It is suggested that the government expands the infrastructure to other smaller towns so that the internet service can be benefitted by more SMEs. SMEs which have implemented E-Commerce should adopt this technology with trained staffs in their businesses to take more advantage of this technology.

\section{Limitation and Future Work}

This study was limited to 3 cities - Karachi, Gujranwala and Faisalabad of Pakistan, and SMEs in other cities in Pakistan might have different adoption and utilization of E-Commerce and E-SCM. Because of time and cost constraints, we surveyed the cities where majority of SMEs were found in abundant number according to SMEDA data list. This study should be extended to cover more SMEs at the national level and further research should survey SMEs from the whole of Pakistan. 
Based on the findings and limitation of this study, future works are proposed. How to make further implementation of E-Commerce needs support from the government to prepare infrastructures so that it can make the diffusion of E-Commerce effectively. SMEDA and others government departments should encourage SMEs to change their concepts and actively participate in E-Commerce and E-SCM development. After that, the Owners/CEOs in SMEs should increase funding and personnel support to E-Commerce project and should be personally involved in the formulation and implementation of E-Commerce and E-SCM.

\section{Acknowledgements}

I am particularly grateful to the Allah Almighty for giving me strength and wisdom to be where I am. Without Him, I am nothing.

I would like to thank my Supervisor Prof. Yan Liang for his valuable and constructive suggestions during the planning, development and finalization of this paper. His willingness to give his time so generously has been very much appreciated. I would also like to extend my thanks to my wife Sumaira Shahzad who is Doctorate students of Geographic Information System, China University of Geosciences, Wuhan, for their information sharing and suggestion during the paper writing.

\section{References}

[1] Turban, E., et al. (2008) A Managerial Perspective. Electronic Commerce 2006, Pearson Education Inc., Upper Saddle River.

[2] Bayraktar, E., Demirbag, M., Koh, S.C.L., Tatoglu, E. and Zaim, H. (2009) A Causal Analysis of the Impact of Information Systems and Supply Chain Management Practices on Operational Performance: Evidence from Manufacturing SMEs in Turkey. International Journal of Production Economics, 122, 133-149. http://dx.doi.org/10.1016/j.ijpe.2009.05.011

[3] Gunasekaran, A. and Ngai, E.W. (2004) Virtual Supply-Chain Management. Production Planning \& Control: The Management of Operations, 15, 584-595. http://dx.doi.org/10.1080/09537280412331283955

[4] Coyle, J.J., Edward, J.B. and Langley, C.J. (2003) The Management of Business Logistics-A Supply Chain Perspective, 7th Edition, Academic Internet Publishers, Mason.

[5] SMEDA Pakistan (2010). http://www.smeda.org.pk/main

[6] Press News Lahore (2014). http://ifcext.ifc.org/IFCExt/pressroom/IFCPressRoom.nsf/0/D2EBF578AB27C6D085257CB30051F040?OpenDocume $\underline{\mathrm{nt}}$

[7] Turban, E., et al. (2008) Information Technology for Management Transforming Organizations in the Digital Economy. 6th Edition, John Wiley \& Sons (Asia) Pte Ltd., Hoboken.

[8] Drayse, M.H. (2011) Globalization and Innovation in a Mature Industry: Furniture Manufacturing in Canada. Regional Studies, 45, 299-318. http://dx.doi.org/10.1080/00343400903241501

[9] Saffu, K., Walker, J.H. and Hinson, R. (2008) Strategic Value and Electronic Commerce Adoption among Small and Medium-Sized Enterprises in a Transitional Economy. Journal of Business \& Industrial Marketing, 23, 395-404. http://dx.doi.org/10.1108/08858620810894445

[10] Molla, A. and Licker, P.S. (2005) E-Commerce Adoption in Developing Countries: A Model and Instrument. Information \& Management, 42, 877-899. http://dx.doi.org/10.1016/j.im.2004.09.002

[11] Premkumar, G., Ramamurthy, K. and Nilakanta, S. (1994) Implementation of Electronic Data Interchange: An Innovation Diffusion Perspective. Journal of Management Information Systems, 11, 157-186.

[12] Levis, K. (1996) Electronic Commerce. British Telecommunications Engineering, 14, 281-285.

[13] Zeng, S.X., Xie, X.M. and Tam, C.M. (2010) Relationship between Cooperation Networks and Innovation Performance of SMEs. Technovation, 30, 181-194. http://dx.doi.org/10.1016/j.technovation.2009.08.003

[14] Jennex, M.E., Amoroso, D. and Adelakun, O. (2004) E-Commerce Infrastructure Success Factors for Small Companies in Developing Economies. Electronic Commerce Research, 4, 263-286.

[15] Zhu, L. and Thatcher, S.M.B. (2010) National Information Ecology: A New Institutional Economics Perspective on Global E-Commerce Adoption. Journal of Electronic Commerce Research, 11, 53-71.

[16] Ghobakhloo, M., Sabouri, M.S., Tang, S.H. and Zulkifli, N. (2011) Information Technology Adoption in Small and Medium-Sized Enterprises: An Appraisal of Two Decades Literature. Interdisciplinary Journal of Research in Business, 1, 53-80. 
[17] Hollenstein, H. and Woerter, M. (2008) Inter- and Intra-Firm Diffusion of Technology: The Example of E-Commerce: An Analysis Based on Swiss Firm-Level Data. Research Policy, 37, 545-564. http://dx.doi.org/10.1016/j.respol.2007.12.006

[18] Crespo, A.H. and Bosque, I.R. (2008) The Effect of Innovativeness on the Adoption of B2C E-Commerce: A Model Based on the Theory of Planned Behaviour. Computers in Human Behavior, 24, 2830-2847. http://dx.doi.org/10.1016/j.chb.2008.04.008

[19] Wang, S. and Cheung, W. (2004) E-Business Adoption by Travel Agencies: Prime Candidates for Mobile E-Business. International Journal of Electronic Commerce, 8, 43-63.

[20] Eastin, M.S. (2002) Diffusion of E-Commerce: An Analysis of the Adoption of Four E-Commerce Activities. Telematics and Informatics, 19, 251-267. http://dx.doi.org/10.1016/S0736-5853(01)00005-3

[21] Gunasekaran, A. and Ngai, E.W. (2004) Virtual Supply Chain Management. Production Planning \& Control, 15, 584595. http://dx.doi.org/10.1080/09537280412331283955

[22] Akyuz, G.A. and Rehan, M. (2009) Requirements for Forming an "E-Supply Chain”. International Journal of Production Research, 47, 3265-3287. http://dx.doi.org/10.1080/00207540701802460

[23] Chuang, M.L. and Shaw, W.H. (2000) Distinguishing the Critical Success Factors between E-Commerce, Enterprise Resource Planning and Supply Chain Management. Proceedings of the 2000 IEEE Engineering Management Society, Albuquerque, 13-15 August 2000, 596-601.

[24] Turban, E., et al. (2008) Information Technology for Management Transforming Organizations in the Digital Economy. 6th Edition, John Wiley \& Sons (Asia) Pte Ltd., Hoboken.

[25] Bordonaba-Juste, V. and Cambra-Fierro, J.J. (2009) Managing Supply Chain in the Context of SMEs: A Collaborative and Customized Partnership with the Suppliers as the Key for Success. Supply Chain Management: An International Journal, 14, 393-402.

[26] Graham, G. and Hardaker, G. (2000) Supply Chain Management across the Internet. International Journal of Physical Distribution and Logistics Management, 30, 286-295.

[27] Vakharia, A.J. (2002) E-Business and Supply Chain Management. Decision Sciences, 33, 495-504. http://dx.doi.org/10.1111/j.1540-5915.2002.tb01653.x

[28] Kumar, R. (1999) Research Methodology: A Step-by-Step Guide for Beginners. Sage Publications, London, Thousand Oaks, New Delhi. 
Scientific Research Publishing (SCIRP) is one of the largest Open Access journal publishers. It is currently publishing more than 200 open access, online, peer-reviewed journals covering a wide range of academic disciplines. SCIRP serves the worldwide academic communities and contributes to the progress and application of science with its publication.

Other selected journals from SCIRP are listed as below. Submit your manuscript to us via either submit@scirp.org or Online Submission Portal.
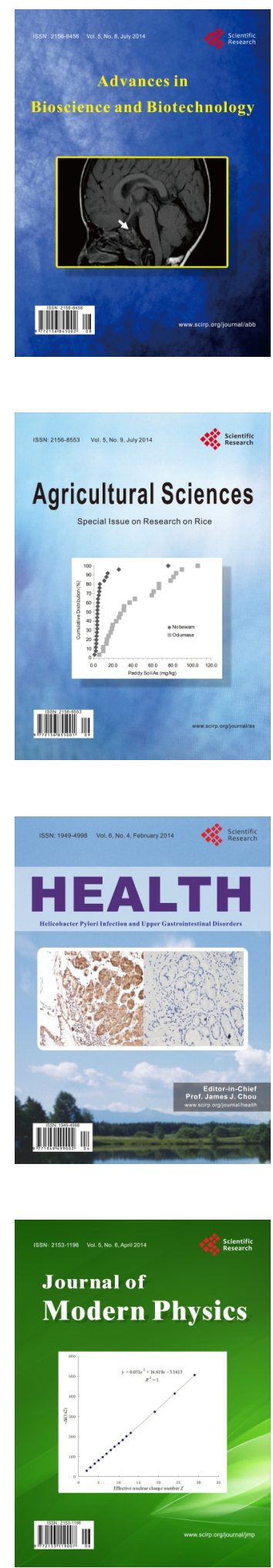
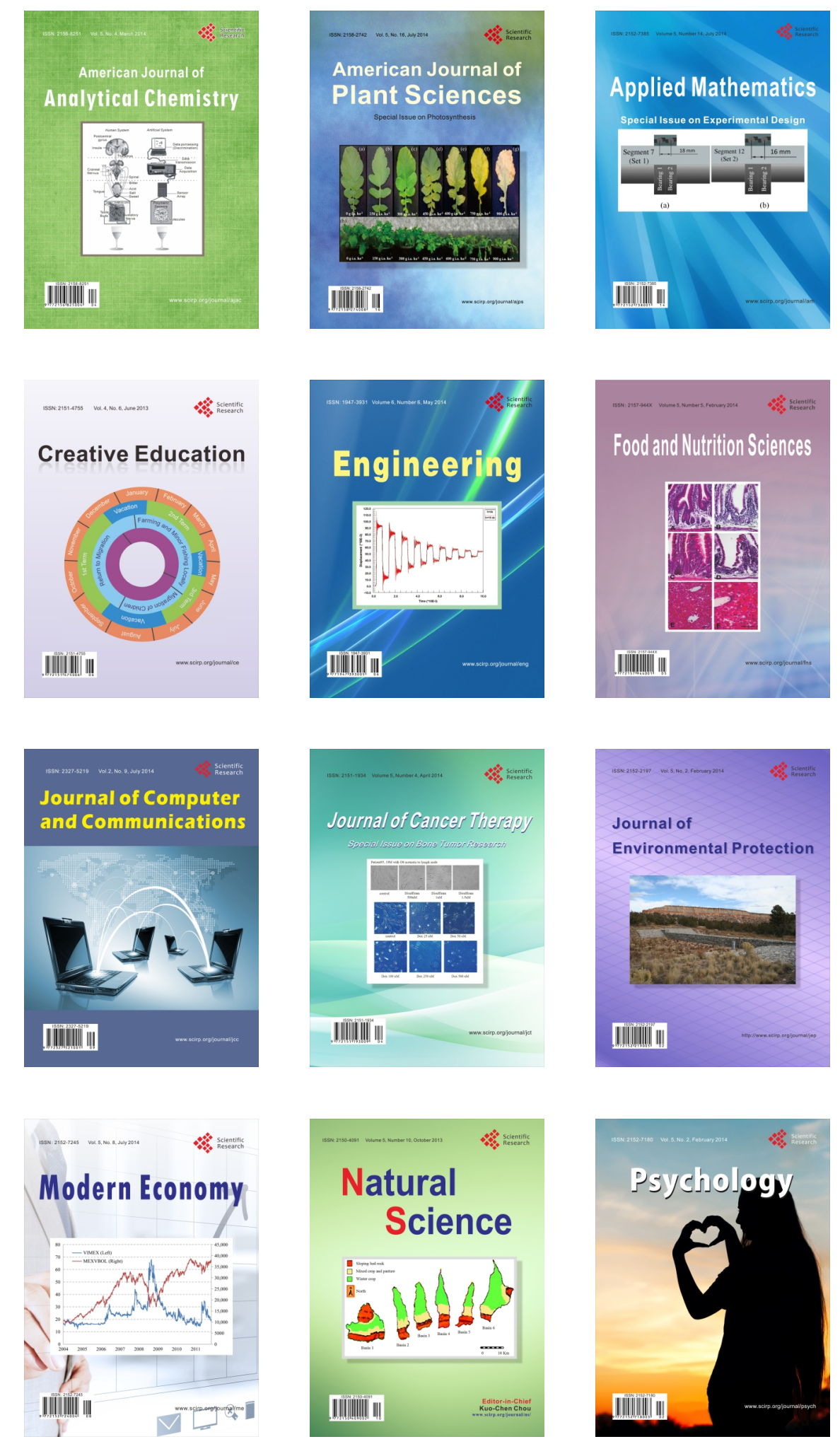